\title{
Libertad, información y la urgencia del desarrollo de las competencias informacionales
}

\section{Pedro Falcato}

Consejo Asesor/ Información, cultura y sociedad

Instituto Nacional de Tecnología Industrial: San Martín, Provincia de Buenos Aires, Argentina / pfalcato@inti.gob.ar /

https://orcid.org/oooo-0002-436o-4694

\section{Resumen}

A partir de experiencias recogidas en actividades de formación de usuarios, se propone una mirada sobre algunas relaciones entre el concepto de información vinculado con la comunicación en la sociedad y con la acción de las personas sobre sí mismas, por un lado, y por otro el desarrollo de competencias informacionales adaptadas a las posibilidades y a los desafíos del mundo actual, como requisito para una mayor libertad.

\section{Palabras clave}

Formación de usuarios Competencias informacionales Libertad

\section{Freedom, information and the urgency of the development of information skills}

\begin{abstract}
Based on experiences gathered in user training activities, some relationships between the concept of information linked to communication in society and the action of people on themselves are analized along with the development of informational skills adapted to the possibilities and the challenges of the current world, as a requirement for greater freedom.
\end{abstract}

Niemand ist mehr Sklave, als der sich für frei hält, ohne es zu sein. (Nadie es más esclavo que quien se tiene por libre y no lo es).

J.W. von Goethe.

Una característica muy notable en el conjunto de los seres vivos es la tendencia al desarrollo de potencialidades, que lleva a una constante evolución. Pasando de la biología al terreno antropológico, histórico y social, podría decirse que nuestra

\section{Keywords}

User training Informational skills Freedom 
civilización tiende a extrapolar de manera falaz, a partir de esa observación, una creencia ingenua en la posibilidad del crecimiento indefinido, regido solo por la voluntad humana, confundiendo desarrollo con aumento.

El crecimiento nos lleva regularmente a encontrar algunos límites más o menos móviles, asociados con la disponibilidad de recursos en una situación dada. Esas situaciones, en el campo económico, han alimentado desde hace más de dos siglos el debate entre la perspectiva malthusiana y quienes consideran que la tecnología puede hacer crecer dichos recursos. Por otra parte, en el ámbito informativo se aprecia un crecimiento casi increíble pero, hasta el momento, parece acotado el interés público en el tema de las posibles limitaciones al tratamiento, almacenamiento y flujo de un volumen de información que se visualiza como siempre creciente.

A partir de lo dicho y de la reflexión sobre experiencias no universalizables pero que conozco directamente, intentaré presentar una perspectiva bibliotecológica sobre el tema planteado en el título de esta nota, entendiendo en este caso al logos más como discurso reflexivo (su sentido primigenio) que como ciencia estrictamente.

Dentro del campo informativo, uno de los primeros recursos que pueden escasear es la capacidad personal para interactuar con grandes masas de recursos informativos; debido a esa escasez, a lo largo de los siglos y especialmente en los últimos tiempos, se elaboraron herramientas y guías de distintos tipos que, según como se las mire, tienen por fin servir como ayudas para encontrar lo que alguien busca, o para filtrar lo que no desea.

Según mi experiencia, no es infrecuente que la capacidad para emplear esas herramientas se naturalice en ciertos imaginarios colectivos como si fuese algo que cualquier persona normal tiene. Por eso, quienes experimentan esa carencia suelen sentirse avergonzados, pero no necesariamente la relacionan con una falta de grados educativos. Hace alrededor de 35 años tuve que encargarme por primera vez de una clase sobre búsqueda de información, orientada en aquel caso al uso de Chemical Abstracts. Me resultó extraño que los concurrentes, universitarios que habían asistido a clases previas relacionadas con el tema, solo supieran usar índices de un tipo, entre los muchos disponibles en esa fuente. Averigüé que ese abordaje les había sido transmitido por alguien que solo conocía dichos índices. Podía decirse que la transmisión de conocimientos técnicos había sido incompleta, era necesario hacerla mejor. En aquel momento, basándome en los modelos de enseñanza que había asimilado en la Facultad, me propuse presentar a esas personas un panorama de las principales características de la fuente en cuestión, para que conociéndolas pudiesen aprovecharla. Entonces no me di cuenta de que había, al menos, otro elemento a considerar: no tenían una visión del proceso informativo en sentido amplio; sin embargo, la conciencia de que ese otro factor existía y era importante, de a poco, fue ganando terreno en mí.

Transcurriendo el tiempo, las clases sobre fuentes se transformaron en cursos más completos sobre la búsqueda de información y estos a su vez evolucionaron hacia la forma de talleres, porque en el desarrollo de las actividades empezó a hacerse evidente que era posible ir más allá del mero intento de efectuar una transmisión desde alguien que supuestamente sabia hacia quienes sabian menos: se podía propiciar que todos aprendiéramos unos de otros, sosteniéndonos en los saberes de cada persona y del grupo, la expresión de sus necesidades, sus capacidades para generar soluciones, dudas, problemas reales y otros factores entre los cuales estaban, por ejemplo, los gustos personales. 
En esas mismas circunstancias quedó expuesto que, junto con el conocimiento de las fuentes, era importante concienciar lo que ocurre cuando la información se origina y fluye en la sociedad, considerando la acción y la intencionalidad de los diversos agentes que intervienen, los sesgos, las limitaciones y toda la problemática social que condiciona el acceso a la información. También se manifestó que, al pensar en el mundo de la información, no conviene suponer que los abordajes a una problemática cualquiera son asépticos y objetivos, aún cuando se trabaje en algún sector que pudiese ser prejuzgado como relativamente neutro en ese sentido, por ejemplo el científico y tecnológico. El desarrollo de las competencias informacionales puede ir, entonces, más allá del conocimiento meramente técnico sobre las características de un determinado recurso, para adentrarse por los caminos de las condiciones sociales de la producción, el flujo y el uso de la información; el contacto con esta faceta es sumamente importante y útil, ya que contribuye a generar competencias para plantear búsquedas, orientarlas y elegir e interpretar los resultados parciales o finales. Esto es aplicable a distintos aspectos de la vida, lo cual aumenta el grado de libertad, que pasa a ser una libertad informada.

En este punto, conviene considerar el significado de información, ya que esta palabra tiene múltiples acepciones. En los talleres antes mencionados, desde hace tiempo se pregunta qué es la información. Importa que cada persona exprese su visión al respecto, porque si nos interesa buscar algo, vale la pena intentar entender qué es eso para nosotros. Los participantes generalmente se sorprenden por la variedad de las definiciones planteadas espontáneamente por ellos mismos.

Es común pensar a la información como una cosa externa a las personas, que puede ser transformada en mercancía, procesada, etc. El vocabulario usado en el ámbito bibliotecario tiende a sostener ese punto de vista: se habla, por ejemplo, de adquisición, procesamiento, almacenamiento, recuperación, etc. El desarrollo de la Bibliotecología, la Documentación y la Ciencia de la Información ha centrado su atención generalmente en lo que ocurre en el universo documentario. Esa mirada es válida, pero apunta solo a una parte del proceso informativo. Hay otra que ocurre en el interior de cada persona, más relacionada con la comunicación y el conocimiento. El sentido del universo documentario se empobrece si se pretende abordarlo siempre aislado de los procesos comunicativos que tienen lugar en la sociedad, por lo cual es conveniente habilitar espacios para reflexionar sobre lo que ocurre en la interacción de las personas con dicho universo. Una biblioteca que sea lugar entre no lugares (Falcato, 2006), puede ser un ámbito especialmente apto y conveniente para generar espacios de ese tipo, en los cuales se aproveche la zona de desarrollo próximo de quienes tengan interés en desarrollar sus competencias informacionales. Esa zona fue descripta por Vygotski (2000: 133) para el caso de los niños como "... la distancia entre el nivel real de desarrollo, determinado por la capacidad de resolver independientemente un problema, y el nivel de desarrollo potencial, determinado a través de la resolución de un problema bajo la guía de un adulto o en colaboración con otro compañero más capaz". El desarrollo pleno de esas competencias no se producirá seguramente a través de una sola actividad, pero allí se puede dar algún paso inicial o de fortalecimiento para que, siguiendo el pensamiento de dicho autor, esas funciones que todavía hoy no son frutos sino todavía capullos o flores, en un mañana próximo sean frutos maduros (Vygotski, 2000: 134).

Para trabajar en una zona de desarrollo próximo con estos asuntos, es importante considerar cuál punto de vista se ha adoptado sobre la información. ¿Es una cosa, una mercancía, un proceso que ocurre en el interior de las personas? 
Lopez Yepes (2015: 131), desde la Documentación, plantea que en dicho campo solo se considera a la información como tal si forma parte de un documento, y que toda documentación es información, pero no toda información es documentación, delineando así el concepto que podemos llamar información documental o documentaria.

Pero también es posible entenderla como un proceso, una acción. De hecho, la primera de las definiciones del Diccionario de la Lengua Española (Real Academia Española, 2019) la plantea como acción y efecto de informar. Notemos que el origen etimológico de informar viene del latín informāre, 'dar forma'.

Entonces, si se trata de colaborar o acompañar a quienes intentan formarse y desarrollar sus competencias informacionales, probablemente una buena aproximación al tema deba tener en cuenta los aspectos procesales internos de la información en las personas y lo que ocurre con ella en los espacios sociales, prestando atención a las interacciones entre el mundo, cada persona y los colectivos.

¿Cómo se traman estos conceptos? ¿Cómo influyen lo que somos, el contexto y quienes están en él, en ese proceso de darnos forma? Al buscar información, ¿el proceso se parece a la búsqueda de un objeto material, o a la de un estado, algo similar a lo que sugerimos al decir 'busco la felicidad' o 'busco la paz'?

Digamos que quien busca no está en medio de la nada, se halla en una situación determinada, lo mismo que aquel que intenta comunicar información. Una búsqueda empieza por la identificación de las necesidades. La comprensión de esas necesidades puede evolucionar desde un estado de menor conciencia hacia uno de mayor conciencia, definición y capacidad de interacción con el mundo, hasta estar en condiciones de satisfacerlas (Taylor ,1968). Quien no conoce cómo es una fuente, debe llegar a entender algunas de sus características para estar en condiciones de aprovecharla. Si la fuente fuese una persona, convendría conocer qué saberes, intereses o capacidades tiene. En cambio, generalmente a las fuentes no personales se las aborda como si no fuesen dispositivos diseñados por personas. Suele verse una preferencia por interactuar con recursos que proporcionan un espacio de búsqueda cuyas características se suponen conocidas, el caso más típico es actualmente Google. Esas características supuestas no siempre son reales, pero incluso se las extrapola y se las emplea como guía para abordar otras fuentes cuyo funcionamiento es distinto. Quien aspira a tener un buen grado de competencias informacionales, debe tener conciencia de las características del espacio en el que la búsqueda se desarrolla. Este puede ser desde una parte de una interfaz que ofrece algún punto de acceso, hasta un conjunto de fuentes o una biblioteca entera. Una búsqueda completa puede incluir sucesivas etapas en uno o más espacios, a medida que una persona o un grupo progresan en el entendimiento de un tema. Esto implica elegir fuentes, así como establecer un orden para abordarlas y las técnicas que se emplearán en cada caso. Por lo general no basta saber cómo buscar en un espacio, sino que hay que determinar en qué espacios, cuándo y cómo buscar. Para ello muchas veces hay que investigar previamente sobre las fuentes disponibles, antes de entrar de lleno en el tema específico, pero no siempre hay conciencia de la complejidad de este campo.

Entre los obstáculos que afectan a los procesos informativos se encuentran las limitaciones y sesgos en la cognición. Uno de ellos es el efecto Dunning-Kruger (Kruger y Dunning, 1999), por el cual una persona evalúa erróneamente su capacidad cognitiva, creyéndola mayor de lo que es. Proviene de la incapacidad para reconocer las propias competencias e incompetencias, debida a la falta de elementos metacognitivos que da lugar a una autoconciencia limitada. Tal vez por eso, en las actividades de formación muchas veces no se inscriben espontáneamente personas que tienen problemas para 
informarse; no advierten que les serviría mejorar sus competencias en el campo. Solamente ante un incidente concreto, como un contacto fortuito con una biblioteca seguido de la solución de un problema y de una explicación e invitación, es que toman conciencia y aceptan participar.

Para procurar la mejora de las competencias informacionales de personas en cuanto usuarias y/o generadoras de información, es conveniente un abordaje que considere, entre otros asuntos, que el proceso informativo en la sociedad habitualmente pasa a través de representaciones e interpretaciones. Supongamos, por ejemplo, que un investigador interactúa con la realidad mediante observaciones, experimentaciones, mediciones, etc. No solo maneja datos crudos, sino que los interpreta, estructura y transforma en un texto o video con el que intenta representar su pensamiento. Ese documento es incorporado a una plataforma después de un proceso de evaluación, modificaciones e indización. La plataforma, a su vez, tiene una interfaz diseñada por humanos, que aporta puntos de acceso y también otros elementos que no son neutros, como la indización, los algoritmos de relevancia o sugerencia, etc. Los usuarios, por su parte, tienen necesidades que pueden ser más o menos reconocidas y elaboradas por ellos mismos, luego intentan representarlas de alguna manera que suponen compatible con los sistemas (por ejemplo mediante palabras sueltas, frases, expresiones booleanas, categorías de una clasificación, etc.) e interactúan con ellos hasta llegar a un punto en el que se produzca o no una coincidencia entre las representaciones que tuvieron origen en ambos extremos de este proceso. Luego quedan otros pasos como la lectura, interpretación, evaluación, asimilación, etc.

Esta narración esquemática pretende poner de relieve que suele haber muchos pasos intermedios entre la realidad y los usuarios de la información, que pueden ser influidos por la acción, intereses o limitaciones de diversas personas y que pueden aportar, modificar o restringir tanto contenidos como semántica.

Incluso en el campo científico y tecnológico, que tal vez parezca un ámbito regido por principios alejados de intereses sectoriales y gustos personales, no todo es aséptico. Un ejemplo tratado en los talleres es el de hablar de seguridad o de riesgos en referencia al uso de un pesticida; ambos términos apuntan a la misma área temática general, pero sus connotaciones son disímiles. La elección de uno $u$ otro por parte del autor de un texto, o del usuario que intenta informarse, indica un punto de vista particular. En el primer caso la connotación podría ser que, si el pesticida es bien usado, no hay ningún problema (posición que podría adoptar, por ejemplo, quien lo produce o vende). La elección del segundo, por su parte, probablemente apunte a lo contrario. Los ejercicios realizados a partir de ejemplos como este, produjeron conclusiones muy interesantes; sobre todo en búsquedas breves, los resultados estuvieron sesgados hacia el primer tipo de planteos o hacia el segundo, según el vocabulario elegido. En el caso de una búsqueda real esto reforzaría, seguramente, los preconceptos de quien efectuara una búsqueda; quien tiene preconceptos ve disminuido su grado de libertad.

En esta época, el acceso abierto a la información se extiende, pero estamos lejos de una libertad de información absoluta. Incluso para que el acceso libre se efectivice, no basta que haya muchos recursos informativos abiertos y que la multiplicidad de medios, rutas y voces haga difícil (aunque no imposible) una censura masiva; el acceso en sí mismo debe concretarse, pero puede estar dificultado no solamente en el caso de sistemas que poseen algún tipo de restricción explícita (medios pagos, orientados a grupos exclusivos, etc.), sino también por otros factores como los excesivos volúmenes de información (por ejemplo, una voz que no es silenciada pero queda 'tapada' por publicaciones de trolls) o por la acción de filtros y recomendaciones, seguramente diseñados originalmente para facilitar los procesos de información, pero que también 
pueden sesgarlos. Ha tenido mucho impacto la idea de Eli Parisier (2011) acerca de las burbujas de filtros, según la cual aquellas herramientas diseñadas para personalizar los resultados de las búsquedas también pueden encerrarnos en un micromundo informativo en el cual imperen únicamente nuestros puntos de vista y preconceptos. Algunos estudios, como el de Nechushtai y Lewis (2019), plantean que ese efecto no es relevante, pero conviene notar que este tema es un buen candidato para aplicar parte de las precauciones expuestas en la presente nota, dado que se relaciona con los servicios de empresas poderosas, con miedos, costumbres, comodidades, modas, prejuicios, etc. Para estudiar el tema en profundidad y no solo casos con poco contexto, hay que hacer algo más que comparar aisladamente elementos tales como los resultados de búsquedas provistos por algún sistema a personas de distintas posiciones políticas. Puedo notar como indicios, por ejemplo, que se usan mis datos de navegación para bombardearme con publicidades personalizadas, o advertir que elijo mis contactos y mis fuentes de información priorizando aquellos más afines, siendo que los dispositivos (teléfonos celulares, computadoras, etc.) tienden a ser medios cada vez más excluyentes para la comunicación. En el mundo real no es tan fácil blindarse contra toda disidencia con mis opiniones, ya que al caminar quedo expuesto tanto a lo que me interesa o me gusta como a lo que no, pero en el mundo virtual los filtros son mucho más eficaces y, en este sentido, potencialmente perniciosos. Es decir: el problema también puede originarse en el hecho de que yo mismo establezco voluntariamente filtros. Sin embargo, hoy en día prácticamente no es posible buscar sin filtrar; por los volúmenes de información actuales, esto suele implicar no llegar a ver muchos recursos informativos posiblemente pertinentes. Recuerdo lo maravilloso que parecía, hace no tantos años, conseguir un poco de información sobre algunos temas. Hoy lo más habitual es que la cantidad de información potencial nos abrume. Como es mucha y está disponible, puede provocarse en nosotros la sensación de que estamos o que fácilmente podemos estar informados, aunque eso no sea más que una mera ilusión a raíz de nuestros sesgos cognitivos o de nuestra limitada capacidad de asimilar. Los sistemas emplean distintas técnicas: tal vez geolocalizan la consulta, priorizan estadísticamente lo que buscan o consultan más personas, etc. y los algoritmos de ordenamiento por estimación de relevancia hacen el resto; pocas personas miran más que un par de páginas de resultados. Es decir, aunque los filtros mostrasen a una persona algo muy semejante a lo que muestran a otras, también se estaría parcializando lo visible; recordemos que, en el ámbito digital actual, lo que no aparece en la pantalla no existe. Por ejemplo, ¿puede ese filtrado impedir que entremos en contacto con algo importante que en un determinado momento no se haga viral, que no logre tener inicialmente repercusión en la suficiente cantidad de personas?

No es a través de lecturas que empecé a darme cuenta de las posibles consecuencias de las burbujas de filtros, sino por un hecho concreto: hace unos años, por curiosidad estuve un rato buscando videos en YouTube sobre una falsa noticia, mientras tenía abierta mi cuenta. A partir de allí, durante días experimenté, o mejor diría, sufrí un bombardeo de sucesivas recomendaciones de videos referidos a ese mismo tema, a pesar de que activamente indicaba al sistema que no me interesaban.

Sea por manipulación o por aceptación, es grave que fenómenos como los descriptos faciliten que haya esclavitudes asumidas sin cadenas, futuros en manos de intereses ajenos o procesos que puedan llevarnos a desastres.

Desde las bibliotecas se puede hacer en el ámbito del desarrollo de las competencias informacionales algo similar a algunos planteos pedagógicos de Paulo Freire, apoyando el "proceso en el que el hombre constituye y conquista, históricamente, su propia 
forma... Esa conquista no se iguala al crecimiento espontáneo de los vegetales: se implica en la ambigüedad de la condición humana, se complica en las contradicciones de la aventura histórica, se explica, o mejor dicho, intenta explicarse en la continua recreación de un mundo que, al mismo tiempo, obstaculiza y provoca el esfuerzo de la superación liberadora de la conciencia humana" (Fiori, 2005: 13).

La libertad es imprescindible pero no basta, desde ella se pueden tomar decisiones sobre qué hacer o no hacer. Eso es seguramente más importante, pero no es el tema del presente editorial. 


\section{Q Referencias bibliográficas}

》Falcato, Pedro.2006. Lugares entre no-lugares. En Información, cultura y sociedad. No. 15, 5-12. <http://revistascientificas.filo.uba.ar/index.php/ICS/article/ view/875> [Consulta: 10 noviembre 2019].

»Fiori, Ernani María. 2005. Aprender a decir su palabra: el método de alfabetización del profesor Paulo Freire [prólogo]. En Freire, Paulo. Pedagogía del oprimido. $2^{\mathrm{a}}$ ed. México: Siglo XXI. p. 11- 27.

"Goethe, Johann Wolfgang von. 1809. Die Wahlverwandtschaften: ein Roman. Theil 2. Tübingen: Cotta. <http://digital.bibliothek.uni-halle.de/download/ $\mathrm{pdf} / 1125198$ ? name $=$ Theil\%202 $>$ [Consulta: 10 noviembre 2019].

"Kruger, Justin y David Dunning. 1999. Unskilled and unaware of it: how difficulties in recognizing one's own incompetence lead to inflated self-assessments. En Journal of personality and social psychology. Vol. 77, no.6, 1121-1134.

»López Yepes, José. 2015. La información en el origen y desarrollo de la Documentación. En JLIS. it, Italian Journal of Library, Archives \& Information Science. Vol. 6, no 2, 126-141.

"Nechushtai, Efrat y Seth C. Lewis. 2019. What kind of news gatekeepers do we want machines to be? Filter bubbles, fragmentation, and the normative dimensions of algorithmic recommendations. En Computers in Human Behavior. Vol. 90, 298-307.

»Parisier, Eli. 2011. The filter bubble: what the Internet is hiding from you. New York: Penguin.

»Real Academia Española. 2019. Diccionario de la Lengua Española. <https://dle. rae.es> [Consulta: 10 noviembre 2019].

»Taylor, Robert S. 1968. Question-negotiation and information seeking in libraries. En College \& research libraries. Vol. 29, no. 3, 178-194

»Vygotski, Lev S. 2000. El desarrollo de los procesos psicológicos superiores. Barcelona: Crítica. 